\title{
Immunomodulatory Effects of Lippia sidoides Extract: Induction of IL-10 Through cAMP and p38 MAPK-Dependent Mechanisms
}

\author{
Arun Rajgopal, John F. Rebhun, Charlie R. Burns, Jeffrey D. Scholten, \\ John A. Balles, ${ }^{2}$ and David J. Fast ${ }^{1}$ \\ ${ }^{1}$ Analytical Sciences, Amway Corporation, Ada, Michigan, USA. \\ ${ }^{2}$ Concentrate Development, Nutrilite, Buena Park, California, USA.
}

\begin{abstract}
Lippia sidoides is an aromatic shrub that grows wild in the northeastern region of Brazil. In local traditional medicine, the aerial portions of this species are used as anti-infectives, antiseptics, spasmolytics, sedatives, hypotensives, and anti-inflammatory agents. In this research, we evaluate the potential immunological properties of Lippia extract through in vitro analysis of its ability to modulate intracellular cyclic adenosine monophosphate (cAMP) levels and interleukin-10 (IL10) production. These results show that Lippia extract increases intracellular cAMP through the inhibition of phosphodiesterase activity. They also demonstrate that Lippia extract increases IL-10 production in THP-1 monocytes through both an increase in intracellular cAMP and the activation of p38 MAPK. These results suggest that the Lippia-mediated inhibition of phosphodiesterase activity and the subsequent increase in intracellular cAMP may explain some of the biological activities associated with $L$. sidoides. In addition, the anti-inflammatory activity of $L$. sidoides may also be due, in part, to its ability to induce IL-10 production through the inhibition of cyclic nucleotide-dependent phosphodiesterase activity and by its activation of the p38 MAPK pathway.
\end{abstract}

KEY WORDS: • anti-inflammatory • cytokines • medicinal plant

\section{INTRODUCTION}

$\boldsymbol{L}$ IPPIA SIDOIDES, POPULARLY KNOWN AS alecrim pimento, is an aromatic shrub that grows wild in the northeastern region of Brazil. ${ }^{1}$ In traditional medicine, the aerial portions of this species are used as anti-infectives, antiseptics, spasmolytics, sedatives, hypotensives, and anti-inflammatory agents. ${ }^{2,3}$ Essential oils extracted from its leaves have been shown to have antimicrobial properties for oral care, reducing gingivitis, and minimizing bone loss and inflammation associated with periodontal disease. ${ }^{1,4-7}$ Its action as an antileishmanial shows that $L$. sidoides may also be an effective alternative treatment for protozoal infections,,${ }^{8,9}$ and the essential oil and hydrolysates have been shown to be effective pesticides against mollusks, ${ }^{10}$ mosquito larvae, ${ }^{11}$ and spider mites. ${ }^{12}$

Elevation of intracellular cyclic adenosine monophosphate (cAMP) activates protein kinase A (PKA)-mediated phosphorylation and activation of cAMP response elementbinding protein (CREB). ${ }^{13}$ Once phosphorylated, CREB is involved in a variety of cellular processes, including prolif-

Manuscript received 6 June 2014. Revision accepted 4 November 2014.

Address correspondence to: David J. Fast, PhD, Analytical Sciences, Amway Corporation, 7575 Fulton Street East, Ada, MI 49355, USA, E-mail: david.fast@amway.com eration, survival, differentiation, and glucose homeostasis. ${ }^{1-16}$ CREB also plays an important role in immune responses, stimulating interleukin-10 (IL-10) production to mediate a feedback loop that limits inflammation, and thereby provides an anti-inflammatory mechanism of action. ${ }^{17}$

During routine screening of botanical extracts, we found that $L$. sidoides (Lippia) extract repeatedly activated a cAMP response element (CRE)-linked luciferase reporter. These results suggest that some of Lippia's medicinal activities may be due, in part, to elevation of intracellular cAMP. In the present study, we sought to determine if the CRE activation is through stimulation of adenylyl cyclase or inhibition of phosphodiesterase. In addition, due to the proposed role of increased cAMP and CRE activation in the stimulation of IL-10, ${ }^{17,18}$ we investigated the potential antiinflammatory action of $L$. sidoides by analyzing the effect of Lippia extract on IL-10 production in human monocytic cells.

\section{MATERIALS AND METHODS}

\section{Plant material and preparation of the extract}

Aerial portions of $L$. sidoides were collected from a crop planted at the Nutrilite farm in Ubajara, Brazil, in the summer of 2008. The identity of the crop (Voucher specimen EAC 54235) was verified by Dr. Ines Cordeiro, 
Nucleus Research Curator of the Herbarium of São Paulo, Institute of Botany, Sao Paulo, Brazil. Aerial portions were air-dried, finely ground with mortar and pestle, and extracted with $85 \%$ ethanol by vortexing for $5 \mathrm{~min}$. Typically, $50 \mathrm{mg}$ of plant material is extracted with $1 \mathrm{~mL}$ solvent. The extract was centrifuged $(250 \mathrm{~g})$ to remove debris and the supernatant transferred to a clean container and evaporated at room temperature using a vacuum concentrator. The dried sample was weighed and reconstituted to $100 \mathrm{mg} / \mathrm{mL}$ in dimethyl sulfoxide.

\section{Cell cultures and generation of stable cell line}

Human embryonic kidney HEK293T cells (CRL-3216) and human acute monocytic leukemia THP-1 cells (TIB202) were purchased from ATCC (Manassas, VA, USA). HEK293T cells were cultured in Dulbecco's modified Eagle's medium and THP-1 cells in RPMI 1640. All cell culture media were supplemented with $10 \%$ fetal bovine serum (FBS), $100 \mathrm{IU} / \mathrm{mL}$ penicillin, $100 \mu \mathrm{g} / \mathrm{mL}$ streptomycin, and $2.5 \mu \mathrm{g} / \mathrm{mL}$ amphotericin B. Cell cultures were grown in a humidified $5 \% \mathrm{CO}_{2}$ atmosphere at $37^{\circ} \mathrm{C}$. Tissue culture reagents were from Mediatech (Manassas, VA, USA), except FBS, which was from HyClone (Logan, UT, USA).

A stable cell line was developed by transfecting a firefly luciferase reporter vector, pGL4.29 [luc2P/CRE/Hygro], from Promega (Madison, WI, USA) into HEK293T cells using Fugene 6 from Roche Applied Science (Indianapolis, IN, USA). The resulting clones were selected and maintained in $200 \mu \mathrm{g} / \mathrm{mL}$ hygromycin supplemented growth media. The vector construct consists of three tandem CRE sequences upstream of the promoter sequence to initiate transduction of the luciferase reporter gene.

\section{CRE-luciferase reporter assay}

Stably transfected HEK293T cells expressing the CREluciferase reporter were plated $\left(6 \times 10^{4}\right.$ cells/well $)$ in whitewalled, clear-bottom 96-well plates and incubated overnight. Cells were treated with select samples/compounds at specified concentrations for $4 \mathrm{~h}$ in a humidified $5 \% \mathrm{CO}_{2}$ incubator at $37^{\circ} \mathrm{C}$. The assay was terminated with a lysis buffer $(20 \mu \mathrm{L} /$ well), D-luciferin (100 $\mu \mathrm{L} /$ well; Biotium, Hayward, CA, USA) was added, and the resulting luminescence was quantified using a SpectraMax M5 microplate reader (Molecular Devices, Sunnyvale, CA, USA). Data analysis was performed using GraphPad Prism Software (La Jolla, CA, USA).

\section{PDE-Glo ${ }^{\mathrm{TM}}$ phosphodiesterase assay}

Phosphodiesterase (PDE) activity was quantitated using the PDE-Glo ${ }^{\mathrm{TM}} \mathrm{PDE}$ assay kit as outlined by the manufacturer (Promega). The PDE activity was measured in 96-well plates using bovine brain PDE (1 mU/well; Sigma-Aldrich, St. Louis, MO, USA), $1 \mu \mathrm{M}$ cAMP or $10 \mu \mathrm{M}$ cyclic guanosine monophosphate (cGMP) per reaction, and the indicated concentrations of test compounds. Sample luminescence was quantified using a SpectraMax M5 microplate reader and data analysis performed using GraphPad Prism Software.

\section{Enzyme-linked immunosorbent assay}

THP-1 cells were differentiated with calcitrol $(5 \mu \mathrm{M}$; Cayman Chemical, Ann Arbor, MI, USA) for 3 days. The differentiated cells were washed and treated overnight with Lippia extract and other compounds (forskolin [Fsk], polymyxin B [PMB], isoproterenol, 8-bromoadenosine$3^{\prime}, 5^{\prime}$-cyclic monophosphate [8-Br-cAMP], SB203580 [SigmaAldrich], and Escherichia coli K12 lipopolysaccharide [LPS; Invivogen, San Diego, CA, USA]). The cultures were incubated for $18 \mathrm{~h}$, at which time the culture supernatants were collected. IL-10 levels in the culture supernatants of THP-1 cells were quantitated by an enzyme-linked immunosorbent assay according to the manufacturer's instructions (MabTech, Cincinnati, OH, USA). All test compounds were titrated before use in IL-10 induction assays to determine concentrations that were nontoxic using the watersoluble tetrazolium viability indicator WST-1 (Roche Applied Science).

\section{Western blot}

THP-1 cells were differentiated with calcitrol as stated above. The differentiated cells were washed and incubated in RPMI-1\% FBS for $3 \mathrm{~h}$, at which time Lippia extract and Fsk were added at $200 \mu \mathrm{g} / \mathrm{mL}$ and $10 \mu \mathrm{M}$, respectively. Pam $_{3} \mathrm{Csk}_{4}$ (Invivogen) was used a positive control $(1 \mu \mathrm{g} / \mathrm{mL})$. Following treatment, cell lysates were made by incubating the cells on ice for $30 \mathrm{~min}$ in a $1 \times$ cell lysis buffer with an added phosphatase inhibitor cocktail containing sodium fluoride, sodium pyrophosphate, $\beta$-glycerophosphate, and sodium orthovanadate (Cell Signaling Technology, Beverly, MA, USA). The lysates were centrifuged for $3 \mathrm{~min}$ at $4000 \mathrm{~g}$ to remove cellular debris. Protein content of the lysates was determined using the BCA protein assay (Pierce, Rockford, IL, USA). Samples (50 $\mu \mathrm{g}$ protein) were electrophoresed on $4-15 \%$ Miniprotean TGX polyacrylamide gels (Bio-Rad, Hercules, CA, USA) and were transferred to an Immobilon-P PVDF membrane (EMD Millipore, Billerica, MA, USA). The blot was blocked with 5\% nonfat dry milk in Tris-buffered salineTween 20 (TBST; Cell Signaling Technology). Rabbit antip38 and anti-P-p38 antibodies (Cell Signaling Technology) were incubated for $18 \mathrm{~h}$ each at $4^{\circ} \mathrm{C}$ and $\mathrm{p} 38$ was probed as a loading control. A donkey anti-rabbit IgG-horseradish peroxidase (HRP) conjugate was used as the secondary antibody (Abcam, Cambridge, MA, USA). Between antibodies, blots were stripped with the Restore Plus Western Blot stripping buffer (Pierce). The blots were developed with ImmunStar HRP substrate (Bio-Rad) on a BioRad ChemiDoc XRS Imaging system.

\section{Statistical analysis}

The results of the experiments described in this study are expressed as mean \pm standard deviation values and are representative of three independent experiments. Statistical analysis was carried out by Student's $t$-test using PRISM version 6.01 statistical analysis software (GraphPad Software, Inc., San Diego, CA, USA). Levels of statistical 
significance between data sets were significant if the $P$-value $<.05(*)$, highly significant if $P<.01(* *)$, and a very high level of significance if $P<.001(* * *)$.

\section{RESULTS}

Effect of Lippia extract, IBMX, and forskolin on CRE-luciferase reporter assay

During a routine screen of plant extracts using a CREluciferase reporter assay, Lippia extract was found to repeatedly activate the luciferase reporter. The response was shown to be concentration dependent with a maximum activity of approximately fourfold over control and an $\mathrm{EC}_{50}$ of $20 \mu \mathrm{g} / \mathrm{mL}$ (Fig. 1). As activation of CREB is dependent on an increase in intracellular levels of cAMP, we wanted to test if the CREB-activating effect of Lippia extract was due to stimulation of adenyl cyclase or inhibition of phosphodiesterase. Therefore, we compared the Lippia extractinduced reporter activity to reporter responses elicited by IBMX and Fsk. IBMX, a nonspecific competitive cAMPand cGMP-dependent phosphodiesterase inhibitor, ${ }^{19}$ increases intracellular cAMP by inhibiting its degradation by phosphodiesterases. Conversely Fsk, a botanical diterpene from Coleus forskohlii, increases intracellular cAMP through direct activation of adenylyl cyclase. ${ }^{20}$ The maximum Lippia extract-induced reporter response was similar in potency to reporter responses to $100 \mu \mathrm{M}$ IBMX and $100 \mathrm{nM}$ of Fsk (Fig. 2).

Effect of IMBX alone and in combination with Fsk or Lippia extract on CRE-luciferase reporter assay

When combined, Fsk and IBMX increase intracellular cAMP levels by simultaneously increasing its production and

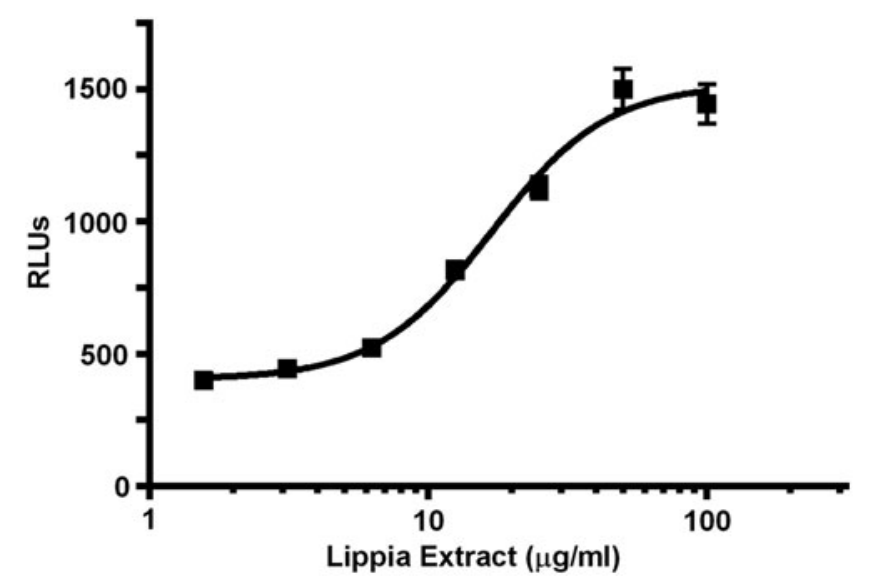

FIG. 1. Effects of Lippia extract on activation of cAMP response element (CRE)-responsive luciferase reporter. HEK293T cells expressing a CRE-responsive luciferase reporter were treated with increasing concentrations $(1.6-100 \mu \mathrm{g} / \mathrm{mL})$ of Lippia extract for $4 \mathrm{~h}$. Results are plotted as relative luminescence units (RLUs) against increasing concentrations of Lippia extract $\left(\mathrm{EC}_{50}=20 \mu \mathrm{g} / \mathrm{mL}\right)$. Results are representative of three separate experiments and data reported as mean \pm one standard deviation (SD).

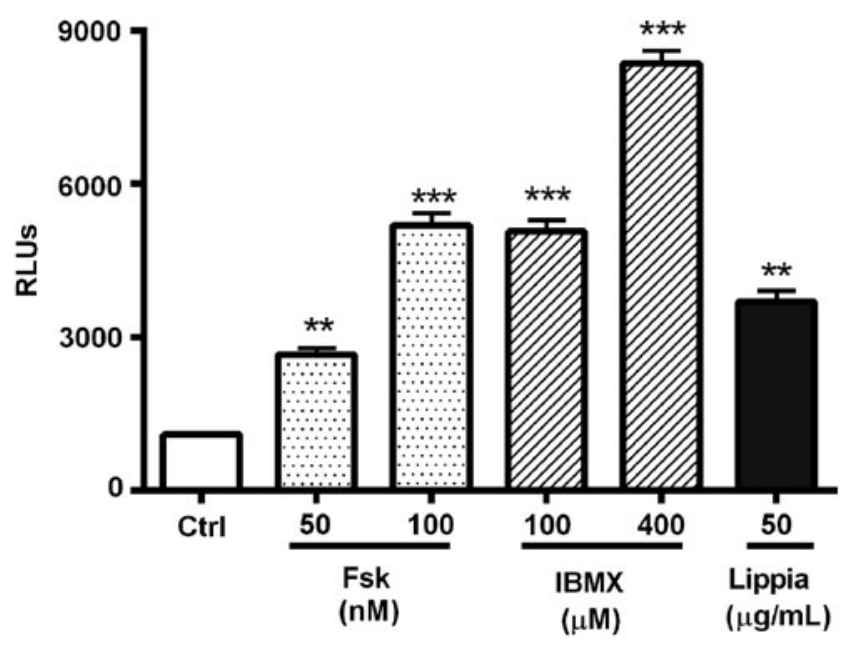

FIG. 2. Effects of forskolin (Fsk), IBMX, and Lippia extract on CRE reporter activity. HEK293T cells expressing a CRE-responsive luciferase reporter were treated with various concentrations of forskolin (50-100 nM), IBMX (100-400 nM), or Lippia extract (50 $\mu \mathrm{g}$ / $\mathrm{mL}$ ) for $4 \mathrm{~h}$. Reporter responses are plotted as RLUs. Results are representative of three separate experiments and data reported as mean \pm 1 SD. ** Represents $P<.01$ and *** represents $P<.001$.

inhibiting its destruction. The maximal response of the CRE reporter cells to the combination of IBMX and Lippia extract was similar to the maximal response elicited by IBMX alone (Fig. 3). In addition, the maximal response elicited by the combination of Lippia extract with Fsk was similar to the maximal response elicited by IBMX with Fsk. The two sets of curves in Figure 3, therefore, suggest that Lippia extract acts through the same mechanism as IBMX and increases cAMP levels through the inhibition of PDE activity.

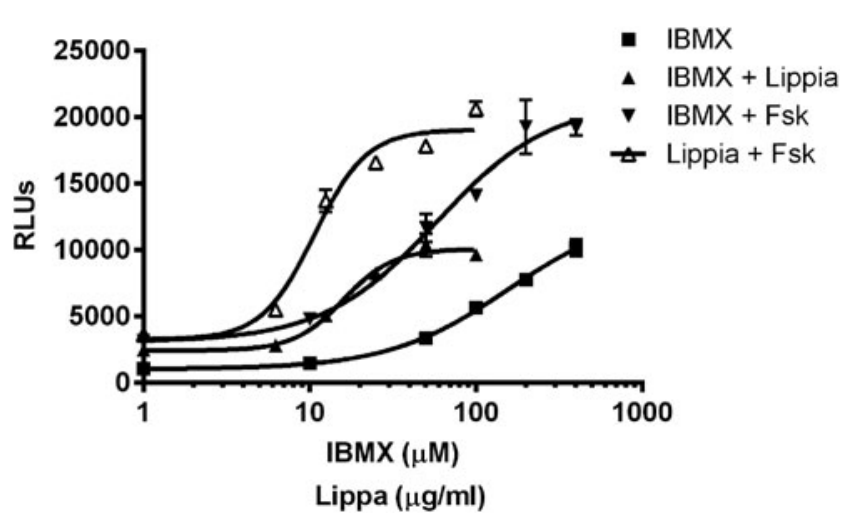

FIG. 3. Effects of IBMX in combination with forskolin and Lippia extract on CRE-luciferase reporter activity. HEK293T cells expressing a CRE-responsive luciferase reporter were treated with IBMX alone $(25-400 \mu \mathrm{M})$ and in the presence of Lippia extract $(100 \mu \mathrm{g} /$ $\mathrm{mL})$; Lippia extract $(6.25-100 \mu \mathrm{g} / \mathrm{mL})$ with Fsk $(100 \mathrm{nM})$, and IBMX $(25-400 \mu \mathrm{M})$ with Fsk $(100 \mathrm{nM})$ for $4 \mathrm{~h}$. The $\mathrm{x}$ axis depicts concentrations of IBMX in $\mu \mathrm{M}$ or Lippia extract in $\mu \mathrm{g} / \mathrm{mL}$. Reporter responses are plotted as RLUs. Results are representative of three separate experiments and data reported as mean \pm 1 SD. 


\section{Effect of Lippia extract on phosphodiesterase activity}

To confirm that Lippia extract inhibits PDE, we tested its effect in the PDE-Glo assay. We demonstrate that Lippia extract inhibits cAMP- and cGMP-dependent phosphodiesterases in a concentration-dependent manner with $\mathrm{IC}_{50}$ of 3 and $25 \mu \mathrm{g} / \mathrm{mL}$, respectively (Fig. 4). Lippia extract did not inhibit the activity of the assay controls, luciferase, and PKA (data not shown).

\section{Effect of Lippia extract on $I L-10$ production} in THP-1 cells

An increase in intracellular cAMP and subsequent activation of CREB has been shown to play a role in IL-10 expression. ${ }^{17,18}$ Since Lippia extract increases intracellular cAMP, it may also induce IL-10 production in immune cells. To test this hypothesis, we investigated the effect of Lippia extract on IL-10 production in calcitrol-differentiated THP-1 cells. Calcitrol-treated THP-1 cells differentiate along a monocytic maturation pathway such that they express CD $11 \mathrm{~b}$ and CD14. ${ }^{21}$ Treatment of differentiated THP-1 cells with Lippia extract (4 and $20 \mu \mathrm{g} / \mathrm{mL}$ ) slightly increased IL-10 levels compared with untreated controls (Fig. 5). Lippia extract was also tested at $100 \mu \mathrm{g} / \mathrm{mL}$, but this concentration was toxic (data not shown). Isoproterenol, a $\beta$-adrenergic receptor agonist shown to induce IL-10 production in a murine macrophage cell line, ${ }^{22}$ was used as a positive control. Undifferentiated THP-1 cells did not produce IL-10 when treated with Lippia extract or isoproterenol (data not shown).

Effect of Lippia extract on IL-10 production in Fsk and 8-Br-cAMP-treated THP-1 cells

To further investigate the potential role of cAMP in the production of IL-10, we treated differentiated THP-1 cells

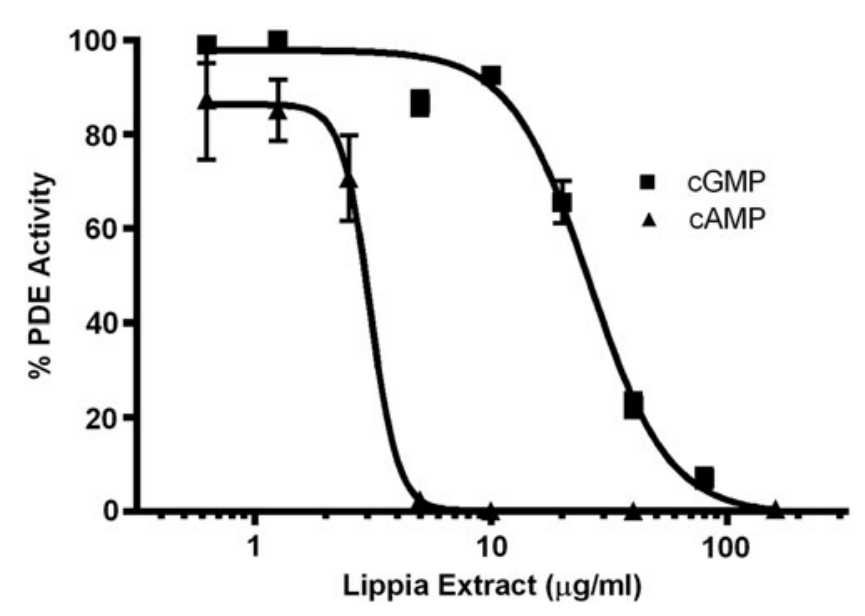

FIG. 4. Effect of Lippia extract on cyclic adenosine monophosphate (cAMP)- and cyclic guanosine monophosphate (cGMP)dependent phosphodiesterases (PDEs). PDE-Glo PDE assay was used to assess the inhibition of Lippia extract $(1.6-160 \mu \mathrm{g} / \mathrm{mL})$ on bovine brain PDE activity. $\mathrm{IC}_{50}$ values were 3 and $25 \mu \mathrm{g} / \mathrm{mL}$ for cAMP- and cGMP-dependent PDEs, respectively. Results are representative of three separate experiments and data reported as mean $\pm 1 \mathrm{SD}$.

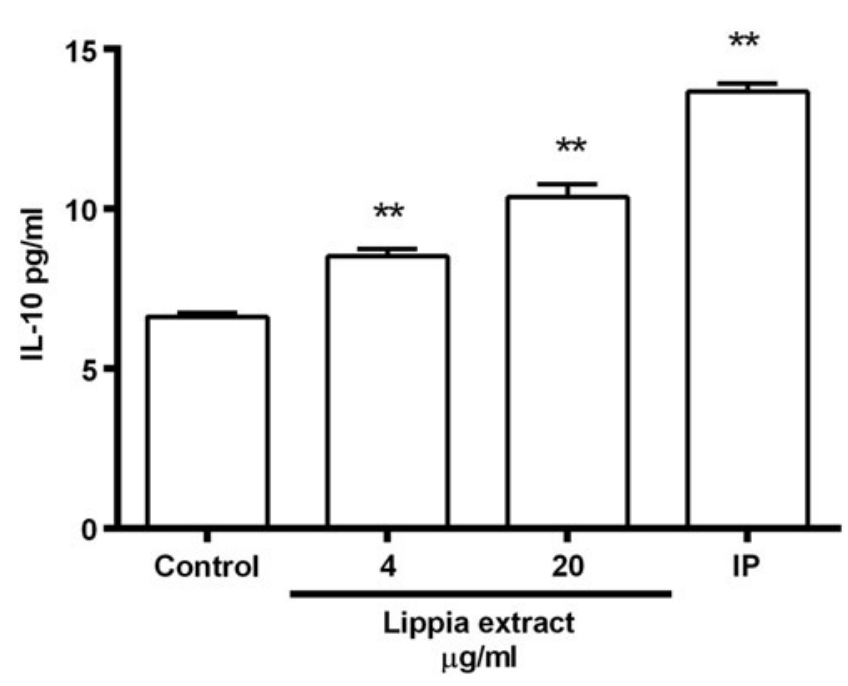

FIG. 5. Effect of Lippia extract on interleukin-10 (IL-10) production in differentiated THP-1 cells. Calcitrol-differentiated THP-1 cells in triplicate were treated with Lippia extract $(4,20 \mu \mathrm{g} / \mathrm{mL})$ for $18 \mathrm{~h}$, after which the cell culture supernatants assayed for IL-10 by enzyme-linked immunosorbent assay (ELISA). Isoproterenol (IP, 100 $\mathrm{nM}$ ) was used as a positive control. Results are representative of three separate experiments and data reported as mean $\pm 1 \mathrm{SD}(* * P<.01)$.

with the adenylyl cyclase activator, Fsk, and the cell permeable cAMP analog, 8-Br-cAMP, alone and in the presence of Lippia extract. Our hypothesis was that by elevating cAMP levels while preventing its degradation through the PDE inhibitory activity of Lippia extract, we might maximize intracellular cAMP levels to a level that is able to maximize IL-10 production. Treatment with Fsk or 8-BrcAMP alone produced an increase in IL-10 production between $25 \%$ and $30 \%$ (Fig. 6). However, when the cells were treated with Lippia extract $(25 \mu \mathrm{g} / \mathrm{mL})$ in combination with either Fsk $(1 \mu \mathrm{M})$ or 8 -Br-cAMP $(100 \mu \mathrm{M})$, net IL-10 production above that of untreated control cells was greater than what might be expected by simply adding the IL-10 responses to each of these reagents singly (Fig. 6). For Fsk and Lippia extract, the net expected additive response would be $\sim 6.9 \mathrm{pg} / \mathrm{mL}$ IL-10, while the actual observed net IL-10 response to the combination of the two was $12.9 \mathrm{pg} / \mathrm{mL}$. Likewise for 8-Br-cAMP, the net expected additive response would be $\sim 8 \mathrm{pg} / \mathrm{mL}$, while the actual observed net IL-10 response was $13.1 \mathrm{pg} / \mathrm{mL}$.

\section{Comparison of Lippia extract and IBMX for effect} on IL-10 production in Fsk-treated THP-1 cells

To further explore the role of the PDE inhibitory activity of Lippia extract in stimulation of IL-10 production, we compared levels of IL-10 production in differentiated THP-1 cells treated with Lippia extract or IBMX, alone and in combination with Fsk. The results demonstrate that the synergistic IL-10 response seen with Lippia extract in combination with Fsk was not mimicked by the treatment of THP-1 cells with a combination of IBMX and Fsk (Fig. 7). Similarly, THP-1 cells treated with rolipram, a cAMP-specific 


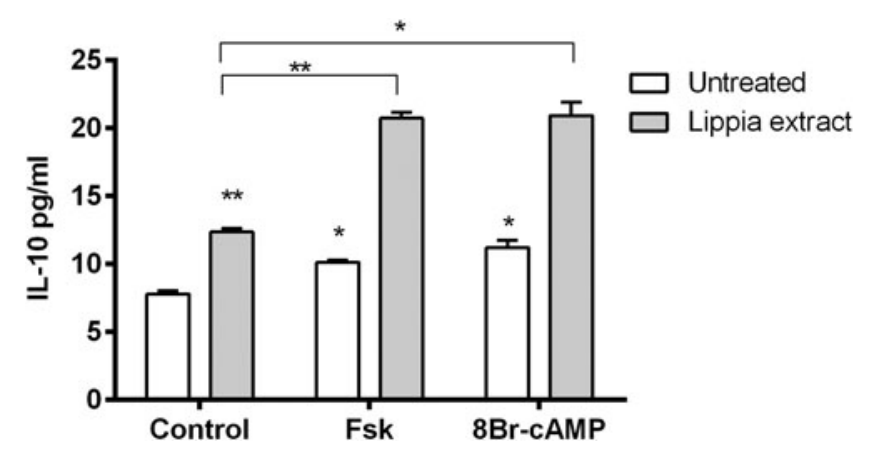

FIG. 6. Effect of Lippia extract with forskolin and 8Br-cAMP on IL-10 production by differentiated THP-1 cells. Calcitrol-differentiated THP-1 cells in triplicate were treated for $18 \mathrm{~h}$ with Lippia extract $(25 \mu \mathrm{g} / \mathrm{mL})$, Fsk $(1 \mu \mathrm{M})$, and 8Br-cAMP $(100 \mu \mathrm{M})$. The following day, cell culture supernatants were assayed for the presence of IL-10 by ELISA. Results are representative of three separate experiments and data reported as mean $\pm 1 \mathrm{SD}(* P<.05, * * P<.01)$. Significance levels for results of cells treated with a single sample and compared with the response of untreated cells are shown above the respective bars. Significance levels for results of cells treated with Lippia extract and Fsk or 8-bromoadenosine-3',5'-cyclic monophosphate (8-BrcAMP) are shown above the connector lines.

PDE inhibitor, in combination with Fsk did not mimic the synergistic IL-10 response seen with Lippia extract in combination with Fsk (data not shown).

Role of p38 MAPK in Lippia extract-stimulated IL-10 production in THP-1 cells

As neither Fsk and IBMX nor the combination of the two stimulated significant production of IL-10, our results suggest that the elevation of intracellular cAMP in response to Lippia extract is not sufficient to account for the Lippia extract-mediated increase in IL-10 production in THP-1 cells. As PKA and p38 MAPK have been shown to play roles in IL-10 expression in response to LPS in a murine

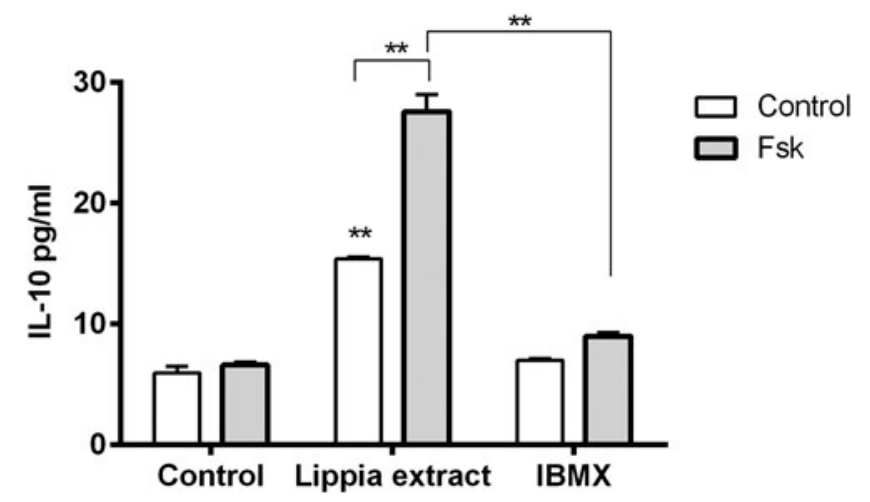

FIG. 7. Effect of IBMX and forskolin on IL-10 production by differentiated THP-1 cells. Calcitrol-differentiated THP-1 cells in triplicate were treated for $18 \mathrm{~h}$ with Lippia extract $(25 \mu \mathrm{g} / \mathrm{mL})$, Fsk $(1 \mu \mathrm{M})$, and IBMX $(100 \mu \mathrm{M})$. The following day, cell culture supernatants were assayed for the presence of IL-10 by ELISA. Results are representative of three separate experiments and data reported as mean $\pm 1 \mathrm{SD}(* P<.5, * * P<.01)$. macrophage cell line, ${ }^{22}$ we tested the effect of specific kinase inhibitors of these pathways on Lippia extract-stimulated IL-10 production (Fig. 8). The PKA inhibitor H89 only partially inhibited the IL-10 response similar to its effect on LPS-stimulated production of IL-10 in RAW 264.7 macrophages. $^{22}$ The p38 MAPK inhibitor SB203580, however, abolished IL-10 produced by cells treated with Lippia extract and Fsk. In addition, western blot analysis confirmed that Lippia extract and Fsk stimulated phosphorylation of p38 that peaked at $60 \mathrm{~min}$.

\section{Effect of Lippia extract on IL-10 production in LPS-treated THP-1 cells}

Finally, as cAMP elevation has been shown to synergize with LPS to induce IL-10 in murine macrophages, ${ }^{22}$ we also tested whether Lippia extract and/or Fsk would synergize with the TLR4 agonist LPS in our model. Treatment of differentiated THP-1 cells with LPS alone induced a modest, but significant, increase in IL-10 production. In addition, treatment of cells with LPS combined with Lippia extract, Fsk, or Lippia extract and Fsk resulted in significant additive increases in IL-10 produced in response to each of these treatment groups (Fig. 9).

Based on these results, however, it was possible that the ability of Lippia extract to induce IL-10 production was due

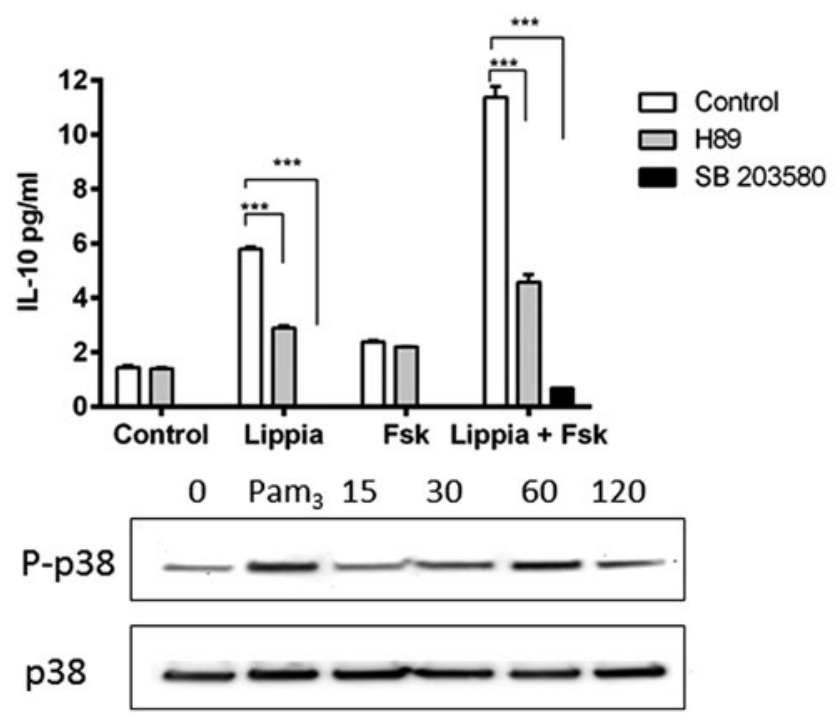

FIG. 8. Effect of protein kinase A (PKA) and p38 MAPK inhibitors on Lippia extract stimulation of IL-10 production in differentiated THP-1 cells. Calcitrol-differentiated THP-1 cells in triplicate were treated for $18 \mathrm{~h}$ with Lippia extract $(25 \mu \mathrm{g} / \mathrm{mL})$ and Fsk $(1 \mu \mathrm{M})$ in the presence of either the PKA inhibitor H89 $(5 \mu \mathrm{M})$ or the p38 MAPK inhibitor SB203580 $(20 \mu \mathrm{M})$. The following day, culture supernatants were assayed for the presence of IL-10 by ELISA. Results are representative of three separate experiments and data reported as mean $\pm 1 \mathrm{SD}(* * * P<.001)$. In addition, phosphorylation of $\mathrm{p} 38$ was assessed by western blot, in which differentiated THP-1 cells were incubated with Lippia extract $(200 \mu \mathrm{g} / \mathrm{mL})$ and Fsk $(10 \mu \mathrm{M})$ for the times shown (min). In addition, $\mathrm{Pam}_{3} \mathrm{Csk}_{4}(1 \mu \mathrm{g} / \mathrm{mL}$ for $30 \mathrm{~min})$ was used as a positive control for p38 phosphorylation. Total p38 was used as a loading control. 


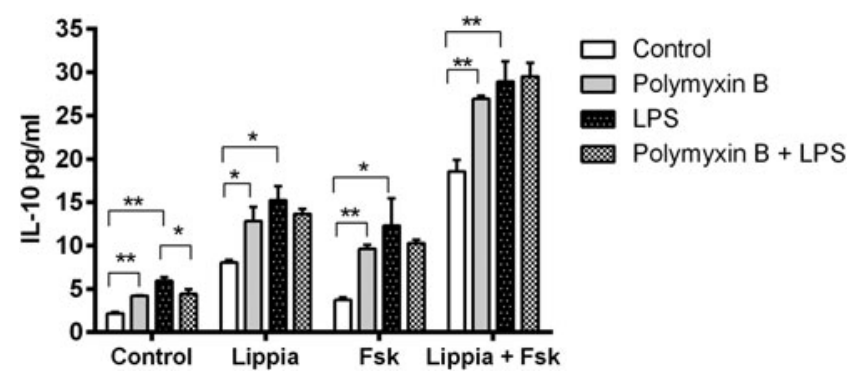

FIG. 9. Effect of TLR agonists and Polymxyin B on Lippia extractinduced IL-10 production by differentiated THP-1 cells. Calcitroldifferentiated THP-1 cells in triplicate were treated for $18 \mathrm{~h}$ with Lippia extract $(25 \mu \mathrm{g} / \mathrm{mL})$, Fsk $(1 \mu \mathrm{M})$, polymyxin B (PMB; $10 \mu \mathrm{g} /$ $\mathrm{mL}$ ), and lipopolysaccharide (LPS; $100 \mathrm{ng} / \mathrm{mL}$ ). The following day, cell culture supernatants were assayed for the presence of IL-10 by ELISA. Results are representative of three separate experiments and data reported as mean \pm 1 SD $(* P<.05, * * P<.01)$. Significance levels are shown above the connector lines.

to the presence of LPS contamination as the Lippia extract was not prepared under pyrogen-free conditions. To exclude this possibility, Lippia extract was treated with PMB, an antibiotic peptide that binds to and neutralizes LPS. ${ }^{23,24}$ Surprisingly, the addition of PMB to cells exposed to Lippia extract, Fsk, or Lippia extract and Fsk had a stimulatory effect on IL-10 production (Fig. 9). As expected, however, PMB inhibited IL-10 produced in response to LPS (100 ng/ $\mathrm{mL}$ ) alone or LPS combined with Lippia extract or Fsk. The addition of PMB had no effect on IL-10 production by cells treated with Lippia extract, Fsk, and LPS, suggesting that the capacity to produce IL-10 by these cells had reached a plateau. To eliminate any complexity that PMB might be adding to our model, we did not include it in any of the other experiments described in this study.

\section{DISCUSSION}

In traditional Brazilian medicine, L. sidoides has been used as an anti-infective, antiseptic, spasmolytic, sedative, hypotensive, and anti-inflammatory agent. ${ }^{2}$ Changes in intracellular cAMP levels are known to affect many of these biological activities. Compounds that inhibit the PDE activity to increase cAMP relax smooth muscles and act as spasmolytics and hypotensives. ${ }^{25}$ An increase in intracellular cAMP reduces inflammatory responses, and compounds that inhibit PDE4 are potential targets to minimize inflammatory diseases. ${ }^{26,27}$ Compounds that increase cAMP have been shown to control pest populations and researchers suggest that plants synthesize PDE inhibitors as part of their defense mechanisms against invasive pests. ${ }^{28,29}$

Despite these medicinal uses, no cAMP-regulating activity has yet to be identified for $L$. sidoides. We propose that many of the medicinal and biological effects of $L$. sidoides are a result of its inhibition of cyclic nucleotide-dependent PDE activity. Our results demonstrate that Lippia extract stimulates cAMP levels as measured by a CRE-luciferase reporter assay (Fig. 1) and that this increase is due to its inhibition of cAMP- and cGMP-dependent PDE activity (Fig. 4).
Since Lippia extract increases intracellular cAMP as evidenced by activation of the CRE luciferase reporter, we expected that it may also induce IL-10 production as CREB activation is known to be involved in IL-10 stimulation pathways. ${ }^{17,18}$ However, while Lippia extract with and without Fsk does stimulate the production of IL-10 by differentiated THP-1 cells (Fig. 5), the inability of the combination of Fsk and the PDE inhibitor, IBMX, to mimic the effect of the combination of Lippia extract and Fsk (Fig. 8) suggests that the extract may increase IL-10 production through an additional pathway besides simply the inhibition of PDE.

As the p38 MAPK pathway and, to a lesser extent, the PKA pathway have been shown to play a role in the LPSstimulated production of IL-10, ${ }^{18,22}$ we also tested the effect of inhibitors of these pathways on Lippia extract-induced IL-10 production. H89 partially inhibited the production of IL-10 in response to Lippia extract alone and in the presence of Fsk. These results support our hypothesis that elevation of cAMP by Lippia extract is not sufficient to induce IL-10 production. In contrast, the p38 inhibitor SB203580 completely inhibited the IL-10 response elicited by Lippia extract and Fsk, suggesting that p38 MAPK is necessary for Lippia extract-induced IL-10 production.

Other signaling pathways have been shown to play a role in the expression of IL-10. In particular, phosphotidylinositol 3-kinase (PI3K) has been shown to be upregulated by calcitrol $^{21,30}$ and to play a role in IL-10 production. ${ }^{31,32}$ It is also interesting to note that curcumin, a component of the spice turmeric, has been shown to enhance IL-10 production in the gut mucosa of patients with inflammatory bowel disease by inhibition of $\mathrm{p} 38 .^{33}$

As mentioned above, bacterial LPS has also been shown to induce IL-10 production through a p38 and MSK-1dependent mechanism in RAW 264.7 macrophages. ${ }^{22}$ The effect of Lippia extract on IL-10 production could, therefore, be explained by the possibility of LPS contamination of the Lippia extract. To rule out this possibility, we tested whether the LPS neutralizing antibiotic, PMB, ${ }^{23,24}$ would eliminate the IL-10-inducing activity of Lippia extract. While PMB did abolish any effects of added LPS in our model, the data in Figure 9 rule out the possibility of LPS contamination as the addition of PMB to Lippia extract and Fsk surprisingly augmented IL-10 production. While it is not in the scope of this work to define the mechanism by which PMB augmented IL-10 production, one possible explanation might be similar to Sugiura et al. who recently demonstrated induction hepatocyte growth factor by PMB in human dermal fibroblasts through MAPK activation. ${ }^{34}$

An additional reason to test whether LPS has an impact on Lippia extract-induced IL-10 production is due to the fact that if Lippia extract were consumed as a medicinal food and was able to encounter myeloid cells in the lamina propria, it is plausible that such cells might also encounter LPS derived from the gut microbiota. LPS added to our model did induce significant increases in IL-10 by itself and in combination with Lippia extract and Fsk. It is tempting, therefore, to speculate that the amount of IL-10 produced in proximity to the intestine may be augmented by Lippia extract in the 
presence of LPS. A possible health benefit, therefore, of enhanced IL-10 production under such conditions might be in controlling intestinal inflammation as IL-10 $10^{-1-}$ mice and people who are low IL-10 producers are prone to development of inflammatory bowel disease. ${ }^{35,36}$

Finally, it may be feasible to utilize $L$. sidoides to facilitate healthy aging. We believe that an efficacious dose is achievable for Lippia extract as the $\mathrm{EC}_{50}$ for the CREB reporter assay was $20 \mu \mathrm{g} / \mathrm{mL}$. While we do not yet know the active ingredient(s) in Lippia extract, for an assumption of $10 \%$ absorption multiplied by an average blood volume of 5 $\mathrm{L}$ of a human adult, the calculated dosage would be $\sim 1 \mathrm{~g}$ of extract per day. As the average mass of a typical nutritional supplement tablet is $500 \mathrm{mg}$, a $1 \mathrm{~g}$ dose is feasible.

Aging is characterized by chronic low-grade inflammation, a phenomenon known as inflammaging, which is thought to contribute to long-term tissue damage and is associated with mortality risk from all causes in older persons. ${ }^{37}$ In addition, inflammation is associated with most conditions that impact health as a person ages. Interestingly, high IL-10 production due to genetic polymorphism is associated with healthy aging, increased longevity, and decreased incidence of Alzheimer's disease. ${ }^{38}$ Therefore, it seems likely that modulating the diet with plants, such as L. sidoides, may increase systemic or local expression of IL-10 to facilitate healthy aging by limiting inflammation and the long-term damage it causes.

In addition, activation of the CREB pathway indirectly inhibits activation of $\mathrm{NF} \kappa \mathrm{B}$ as CREB competes for the coactivator proteins, $\mathrm{CBP}$ and $\mathrm{p} 300$, that are also involved in $\mathrm{NF} \kappa \mathrm{B}$ activation. ${ }^{17}$ We have tested Lippia extract in an IL-1 $\beta$-stimulated $\mathrm{NF} \kappa \mathrm{B}$-luciferase reporter assay and have found that Lippia extract inhibits the response (D. Fast, unpublished observation). Therefore, Lippia may also inhibit production of inflammatory mediators under the control of $\mathrm{NF} \kappa \mathrm{B}$, such as IL-6, IL-8, $\mathrm{PGE}_{2}$, and nitric oxide.

In conclusion, these results demonstrate that $L$. sidoides extract increases intracellular cAMP through inhibition of phosphodiesterase activity. We propose that this activity may explain some of the traditional medicinal activities associated with $L$. sidoides. In addition, the anti-inflammatory activity of Lippia may also be due, in part, to its ability to induce IL-10 production through the inhibition of cyclic nucleotide-dependent PDE activity and through activation of the p38 MAPK.

\section{ACKNOWLEDGMENTS}

The authors would like to thank Barbara Olson for her critical review and subsequent editing of this article and Mr. Andre Terra for his help in verifying the identity of the Lippia sidoides crop. The authors also thank Jeff North and Mark Proefke for their support and scientific discussions of this research.

\section{AUTHOR DISCLOSURE STATEMENT}

All authors are employees of Amway Global, which wholly funded this research.

\section{REFERENCES}

1. Botelho MA, Nogueira NAP, Bastos GM, et al.: Antimicrobial activity of the essential oil from Lippia sidoides, carvacrol and thymol against oral pathogens. Braz J Med Biol Res 2007;40:349-356.

2. Pascual ME, Slowing K, Carretero E, Sánchez Mata D, Villar A: Lippia: traditional uses, chemistry and pharmacology: a review. $J$ Ethnopharmacol 2001;76:201-214.

3. Monteiro MVB, de Melo Leite AKR, Bertini LM, de Morais SM, Nunes-Pinheiro DCS: Topical anti-inflammatory, gastroprotective and antioxidant effects of the essential oil of Lippia sidoides Cham. leaves. J Ethnopharmacol 2007;111:378-382.

4. Botelho MA, Bezerra Filho JG, Correa LL, et al.: Effect of a novel essential oil mouthrinse without alcohol on gingivitis: a double-blinded randomized controlled trial. J Appl Oral Sci 2007; 15:175-180.

5. Botelho MA, Rao VS, Montenegro D, et al.: Effects of a herbal gel containing carvacrol and chalcones on alveolar bone resorption in rats on experimental periodontitis. Phytother Res 2008;22:442-449.

6. Girao VCC, Nunes-Pinheiro DCS, Morais SM, Sequeira JL, Gioso MA: A clinical trial of the effect of a mouth-rinse prepared with Lippia sidoides Cham essential oil in dogs with mild gingival disease. Prev Vet Med 2003;59:95-102.

7. Lobo PLD, Fonteles CSR, de Carvalho CBM, et al.: Dose-response evaluation of a novel essential oil against Mutans streptococci in vivo. Phytomedicine 2011;18:551-556.

8. Moreira JS, Almeida RG, Tavares LS, et al.: Identification of botryticidal proteins with similarity to NBS-LRR proteins in rosemary pepper (Lippia sidoides Cham.) flowers. Protein J 2011;30:32-38.

9. Oliveira VC, Moura DM, Lopes JA, de Andrade PP, da Silva NH, Figueiredo RC: Effects of essential oils from Cymbopogon citratus (DC) Stapf., Lippia sidoides Cham., and Ocimum gratissimum L. on growth and ultrastructure of Leishmania chagasi promastigotes. Parasitol Res 2009;104:1053-1059.

10. Craveiro AA, Alencar JW, Matos FJA, Andrade CHS, Machado MIL: Essential oils from Brazilian verbenaceae. Genus Lippia. J Nat Prod 1981;44:598-601.

11. Carvalho AF, Melo VM, Craveiro AA, Machado MI, Bantim MB, Rabelo EF: Larvicidal activity of the essential oil from Lippia sidoides Cham. Against Aedes aegypti linn. Mem Inst Oswaldo Cruz 2003;98:569-571.

12. Cavalcanti SCH, Niculau ES, Blank AF, Camara CAG, Araujo IN, Alves PB: Composition and acaricidal activity of Lippia sidoides essential oil against two-spotted spider mite (Tetranychus urticae Koch). Bioresour Technol 2009;101:829-832.

13. Gonzalez GA, Montminy MR: Cyclic AMP stimulates somatostatin gene transcription by phosphorylation of CREB at serine 133. Cell 1989;59:675-680.

14. Mayr B, Montminy M: Transcriptional regulation by the phosphorylation-dependent factor CREB. Nat Rev Mol Cell Biol 2001;2:599-609.

15. Shaywitz AJ, Greenberg ME: CREB: a stimulus-induced transcription factor activated by a diverse array of extracellular signals. Annu Rev Biochem 1999;68:821-861.

16. Sakamoto KM, Frank DA: CREB in the pathophysiology of cancer: implications for targeting transcription factors for cancer therapy. Clin Cancer Res 2009;15:2583.

17. Wen AY, Sakamoto KM, Miller LS: The role of the transcription factor CREB in immune function. J Immunol 2010;185:6413. 
18. Saraiva M, O'Garra A: The regulation of IL-10 production by immune cells. Nat Rev Immunol 2010;10:170-181.

19. Robison GA, Sutherland EW: Cyclic AMP and the function of eukaryotic cells: an introduction. Ann N Y Acad Sci 1971;185: 5-9.

20. Seamon KB, Padgett W, Daly JW: Forskolin: unique diterpene activator of adenylate cyclase in membranes and in intact cells. Proc Natl Acad Sci USA 1981;78:3363-3367.

21. Hmama Z, Nandan D, Sly L, Knutson KL, Herrera-Velit P, Reiner NE: 1, 25-Dihydroxyvitamin D3-induced myeloid cell differentiation is regulated by a vitamin D receptor-phosphatidylinositol 3-kinase signaling complex. J Exp Med 1999; 190:1583.

22. Avni D, Ernst O, Philosoph A, Zor T: Role of CREB in modulation of TNF [alpha] and IL-10 expression in LPS-stimulated RAW264. 7 Macrophages. Mol Immunol 2010;47:1396-1403.

23. Cooperstock MS: Inactivation of endotoxin by polymyxin B. Antimicrob Agents Chemother 1974;6:422.

24. Cardoso LS, Araujo MI, Goes AM, Pacifico LG, Oliveira RR, Oliveira SC: Polymyxin B as inhibitor of LPS contamination of Schistosoma mansoni recombinant proteins in human cytokine analysis. Microb Cell Fact 2007;6:1.

25. Banner KH, Press NJ: Dual PDE3/4 inhibitors as therapeutic agents for chronic obstructive pulmonary disease. $\mathrm{Br} J$ Pharmacol 2009;157:892-906.

26. Houslay MD, Schafer P, Zhang KYJ: Keynote review: phosphodiesterase-4 as a therapeutic target. Drug Discov Today 2005;10:1503-1519.

27. Teixeira MM, Gristwood RW, Cooper N, Hellewell PG: Phosphodiesterase (PDE)4 inhibitors: anti-inflammatory drugs of the future? Trends Pharmacol Sci 1997;18:164-171.

28. Hollingsworth RG, Armstrong JW, Campbell E: Caffeine as a repellent for slugs and snails. Nature 2002;417:915-196.

29. Nathanson JA: Caffeine and related methylxanthines: possible naturally occurring pesticides. Science 1984;226:184.
30. Moeenrezakhanlou A, Nandan D, Shephard L, Reiner NE: 1a \pm ,25-Dihydroxycholecalciferol activates binding of CREB to a CRE site in the CD14 promoter and drives promoter activity in a phosphatidylinositol-3 kinase-dependent manner. J Leukoc Biol 2007;81:1311-1321.

31. Polumuri SK, Toshchakov VY, Vogel SN: Role of phosphatidylinositol-3 kinase in transcriptional regulation of TLR-induced IL-12 and IL-10 by Fcgamma receptor ligation in murine macrophages. J Immunol 2007;179:236.

32. Martin M, Rehani K, Jope RS, Michalek SM: Toll-like receptormediated cytokine production is differentially regulated by glycogen synthase kinase 3. Nat Immunol 2005;6:777-784.

33. Epstein J, Docena G, MacDonald TT, Sanderson IR: Curcumin suppresses p38 mitogen-activated protein kinase activation, reduces IL-1b and matrix metalloproteinase-3 and enhances IL-10 in the mucosa of children and adults with inflammatory bowel disease. Br J Nutr 2010;103:824-832.

34. Sugiura Y, Hiramatsu K, Hamauzu R, et al.: Mitogen-activated protein kinases-dependent induction of hepatocyte growth factor production in human dermal fibroblasts by the antibiotic polymyxin B. Cytokine 2012;60:205.

35. Tagore A, Gonsalkorale W, Pravica V, et al.: Interleukin-10 (IL10) genotypes in inflammatory bowel disease. Tissue Antigens 1999;54:386-390.

36. Rennick DM, Fort MM: Lessons from genetically engineered animal models. XII. IL-10-deficient IL-10 (-/-) mice and intestinal inflammation. Am J Physiol Gastrointest Liver Physiol 2000;278:G829-G833.

37. Franceschi C, Bonafè $\mathrm{M}$, Valensin S, et al.: Inflamm-aging: an evolutionary perspective on immunosenescence. Ann N Y Acad Sci 2000;908:244-254.

38. Lio D, Scola L, Crivello A, et al.: Inflammation, genetics, and longevity: further studies on the protective effects in men of IL10-1082 promoter SNP and its interaction with TNF-alpha-308 promoter SNP. J Med Genet 2003;40:296-299. 